\title{
RESEARCH
}

Open Access

\section{Soluble amyloid beta levels are elevated in the white matter of Alzheimer's patients, independent of cortical plaque severity}

Lyndsey E Collins-Praino ${ }^{1,2}$, Yitshak I Francis ${ }^{1}$, Erica Y Griffith ${ }^{1}$, Anne F Wiegman ${ }^{1}$, Jonathan Urbach', Arlene Lawton ${ }^{1}$, Lawrence S Honig ${ }^{1,3}$, Etty Cortes ${ }^{4}$, Jean Paul G Vonsattel ${ }^{4}$, Peter D Canoll ${ }^{4}$, James E Goldman ${ }^{1,4}$ and Adam M Brickman ${ }^{1,3^{*}}$

\begin{abstract}
Alzheimer's disease (AD) is the most common neurodegenerative disease and the leading cause of dementia. In addition to grey matter pathology, white matter changes are now recognized as an important pathological feature in the emergence of the disease. Despite growing recognition of the importance of white matter abnormalities in the pathogenesis of $A D$, the causes of white matter degeneration are still unknown. While multiple studies propose Wallerian-like degeneration as the source of white matter change, others suggest that primary white matter pathology may be due, at least in part, to other mechanisms, including local effects of toxic A peptides. In the current study, we investigated levels of soluble amyloid-beta $(A \beta)$ in white matter of $A D$ patients $(n=12)$ compared with controls $(n=10)$. Fresh frozen white matter samples were obtained from anterior (Brodmann area 9) and posterior (Brodmann area 1, 2 and 3) areas of post-mortem AD and control brains. ELISA was used to examine levels of soluble $A \beta-42$ and $A \beta-40$. Total cortical neuritic plaque severity rating was derived from individual ratings in the following areas of cortex: mid-frontal, superior temporal, pre-central, inferior parietal, hippocampus (CA1), subiculum, entorhinal cortex, transentorhinal cortex, inferior temporal, amygdala and basal forebrain. Compared with controls, $A D$ samples had higher white matter levels of both soluble $A \beta-42$ and $A \beta-40$. While no regional white matter differences were found in $A \beta-40, A \beta-42$ levels were higher in anterior regions than in posterior regions across both groups. After statistically controlling for total cortical neuritic plaque severity, differences in both soluble $A \beta-42$ and $A \beta-40$ between the groups remained, suggesting that white matter $A \beta$ peptides accumulate independent of overall grey matter fibrillar amyloid pathology and are not simply a reflection of overall amyloid burden. These results shed light on one potential mechanism through which white matter degeneration may occur in AD. Given that white matter degeneration may be an early marker of disease, preceding grey matter atrophy, understanding the mechanisms and risk factors that may lead to white matter loss could help to identify those at high risk and to intervene earlier in the pathogenic process.
\end{abstract}

Keywords: Dementia, Neurodegenerative disease, Pathology, Myelin, Ageing, ELISA

\footnotetext{
* Correspondence: amb2139@columbia.edu

'Taub Institute for Research on Alzheimer's Disease and the Aging Brain, College of Physicians and Surgeons, Columbia University, 630 West 168th Street, New York, NY 10032, USA

${ }^{3}$ Department of Neurology, College of Physicians and Surgeons, Columbia University, New York, NY, USA

Full list of author information is available at the end of the article
}

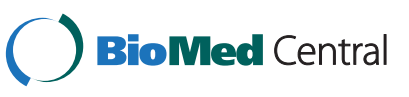

(C) 2014 Collins-Praino et al.; licensee BioMed Central Ltd. This is an Open Access article distributed under the terms of the Creative Commons Attribution License (http://creativecommons.org/licenses/by/4.0), which permits unrestricted use, distribution, and reproduction in any medium, provided the original work is properly credited. The Creative Commons Public Domain Dedication waiver (http://creativecommons.org/publicdomain/zero/1.0/) applies to the data made available in this article, unless otherwise stated. 


\section{Introduction}

Alzheimer's disease (AD) is the most common neurodegenerative disease and the leading cause of dementia [1]. Pathologically, AD is characterized by neuronal loss, amyloid-beta $(A \beta)$ plaques, composed of aggregations of amyloid peptides, and neurofibrillary tangles (NFT), consisting of hyperphosphorylated tau protein. The "amyloid cascade hypothesis", currently the prevailing hypothesis regarding $\mathrm{AD}$ pathogenesis, states that $\mathrm{A} \beta-42$ peptides aggregate to form toxic $A \beta-42$ oligomers and plaques, which then trigger a cascade of neuropathological events, including neuroinflammation, oxidative stress, tau hyperphosphorylation and NFT formation, and, ultimately, widespread neurodegeneration and dementia [2].

Although AD has traditionally been considered a disease of the grey matter, in recent years, white matter changes have come to be recognized as an important pathological feature $[3,4]$. Using structural magnetic resonance imaging (MRI), both white matter atrophy [5-8] and white matter lesions that appear as areas of white matter hyperintensity (WMH) on T2-weighted magnetic resonance imaging (MRI) sequences [9-13] have been reported in AD. At the microstructural level, diffusion tensor imaging (DTI) studies found reductions in white matter integrity in AD patients in multiple white matter regions [3,14-22]. In neuropathology studies, white matter abnormalities have been found to occur in more than $50 \%$ of AD cases [23], and include axonal defect and loss, demyelination, death of oligodendrocytes, reactive astrocytosis and microglial activation [23-33]. White matter abnormalities are associated with performance across a range of neuropsychological tests [34], and predict $A D$ incidence and rate of cognitive decline in the community [9,35-37]. Although once thought to occur secondary to grey matter degeneration, recent studies demonstrated that some white matter changes in $\mathrm{AD}$ may occur independently of and precede grey matter atrophy $[3,4]$.

Despite the growing recognition of the importance of white matter abnormalities in the pathogenesis of $\mathrm{AD}$, the pathological basis of white matter degradation remains to be elucidated. While multiple studies attributed white matter degeneration to concomitant small vessel disease [23,32] or Wallerian-like degeneration [4,32], others suggest that primary white matter pathology may be due, at least in part, to other mechanisms, including toxic $A \beta$ peptides [4]. To investigate this possibility further, we measured levels of soluble $A \beta-40$ and $A \beta-42$ peptides in postmortem cerebral white matter from $A D$ patients and non-AD controls. We elected to measure soluble amyloid levels as, in recent years, extensive evidence has accumulated to suggest that it is the levels of soluble $A \beta$ oligomers, rather than insoluble $A \beta$ fibrils, that correlate with the extent of synaptic loss and the severity of cognitive impairment in AD [38-44]. Given the amyloid cascade hypothesis [2] and the known increase in $A \beta$ in $A D$ brains, we hypothesized that $A D$ patients would show increased white matter levels of soluble $A \beta-40$ and $A \beta-42$ peptides compared with non-AD controls. We also hypothesized that white matter amyloid beta levels would still be increased in AD brains, even after statistically controlling for cortical plaque severity, suggesting that soluble forms of amyloid in the white matter of $\mathrm{AD}$ patients may not merely be a reflection of overall amyloid pathology, but rather could independently contribute to the pathophysiology of the disease. While neuropathological studies have shown that the frontal lobes appear to be the most severely affected by white matter abnormalities [23], we have found using structural MRI that frank white matter damage to more posterior areas is associated with incident AD $[9,35]$. Given this disparity between pathological and imaging findings, the current study also used tissue sections from both anterior and posterior sections to investigate whether white matter amyloid beta levels vary as a function of region.

\section{Materials and methods}

\section{Participants and neuropathological assessment}

Twenty-two cases from the New York Brain Bank at Columbia University were included in the current study (see Table 1 for demographic information). Twelve of these cases were pathologically diagnosed as $\mathrm{AD}$ and 10 were non-AD controls. Within the control group, 3 cases were pathologically normal, 4 were classified pathologically as ischemic stroke without vascular dementia, 1 was classified with progressive supranuclear palsy, 1 with idiopathic Parkinson's disease and 1 with lobar atrophy without Picks disease. Neuropathological assessment was performed blind to clinical diagnosis and diagnosis of $\mathrm{AD}$ was based on CERAD criteria [45]. Of the twelve clinical AD patients, eight had definite AD and four had probable AD based upon CERAD criteria [46]. Of the ten nonAlzheimer's controls, nine did not meet CERAD criteria for $\mathrm{AD}$ and one was classified as having a low probability of $\mathrm{AD}$ [46]. As these are historic cases, they have not been re-evaluated according to the more recent National Institute on Aging-Alzheimer's Association (NIA-AA) criteria. In addition to CERAD criteria, however, diagnosis was confirmed by also rating each case according to the Braak and Braak neuropathological staging criteria for Alzheimer-related changes [47] and the recommendations

Table 1 Demographic data

\begin{tabular}{lll}
\hline & AD $(\mathbf{n}=\mathbf{1 2})$ & Non-AD controls $(\mathbf{n = 1 0})$ \\
\hline Age, years, mean (SD) & $89.00(10.43)$ & $81.00(7.70)$ \\
Male, \% & $25 \%$ & $50 \%$ \\
Black, \% & $8.33 \%$ & $20 \%$ \\
Hispanic, \% & $33.33 \%$ & $30 \%$ \\
\hline
\end{tabular}


of the National Institute on Aging and Reagan Institute (NIA-RI) [48]. Together, these three ratings are largely equivalent to the more contemporary NIA-AA criteria [49]. Within the Alzheimer's group, the ApoE status of nine of the twelve cases was known; of these, four had an $\varepsilon 4$ allele. The ApoE status of nine of the ten cases in the non-Alzheimer's control group was known; of these, three had an $\varepsilon 4$ allele.

This research was reviewed by the Chair of the Columbia University Medical Center Institutional Review Board, who deemed the work exempt from further review (under 45 CFR 46) because there was no interaction with human subjects, no intervention, and private, identifiable information was not collected.

The tissue processing procedure has been described in detail previously [45]. Briefly, the whole fresh brain was first examined grossly, photographed and weighed. The brain was then divided into two halves. One half brain was processed fresh and frozen samples banked for research. The other half brain was formalin fixed processed for thorough neuropathological evaluation.

\section{White matter dissection}

For the current study, fresh frozen tissue blocks from Brodmann area (BA) 1, 2, and 3 (primary somatosensory cortex, posterior sections) and BA9 (dorso-lateral prefrontal cortex, anterior sections) were utilized. White matter was manually dissected from each block on dry ice to prevent thawing of the tissue and frozen at $-80^{\circ} \mathrm{C}$ until biochemical analysis.

\section{Analysis of amyloid levels}

White matter samples (2 g each) were homogenized via sonication on ice in $880 \mu \mathrm{L}$ of tissue lysate buffer (20 mM Tris- $\mathrm{HCl}$ (pH 7.4), $1 \mathrm{mM}$ EDTA, $1 \mathrm{mM}$ ethyleneglycoltetraacetic acid, $250 \mathrm{mM}$ sucrose) supplemented with protease inhibitors (Roche). The tissue homogenates were treated with diethanolamine to extract soluble $A \beta$ and centrifuged at $100,000 \times$ g for 60 minutes at $4^{\circ} \mathrm{C}$. The definition of soluble versus insoluble $A \beta$ was the same as that used in previous studies $[40,50]$ : that is, molecules that remain in the aqueous supernatant after centrifugation for 1 hour are considered soluble $A \beta$, while those $A \beta$ aggregates that remain in the pellet are considered as insoluble $A \beta$. The supernatant was collected, total protein concentration was determined by a BCA protein assay (Thermo Scientific) and homogenate concentrations were standardized. $A \beta-40$ levels were determined using the $A \beta-40$ Type II ELISA kit from Wako (Catalog Number: 292-64701). A $\beta-42$ levels were measured using the $A \beta-42$ High Sensitivity ELISA kit from Wako (Catalog number: 292-64501). These kits have been extensively validated in previous studies (e.g. [51-55]) and are known to show extremely high sensitivity and reproducibility [54]. Both ELISA assays were performed in accordance with the manufacturer's protocol, and all samples were run in duplicate. Optical density values were measured at $450 \mathrm{~nm}$ using a microplate reader, and then converted to concentrations (pmol/L) based on a standard curve. For cortical amyloid plaque ratings, a trained pathologist examined individual tissue sections and the number of $A \beta$ plaques was manually counted. Neuritic plaque severity was rated in one section of each of the following areas from the fixed hemisphere: mid-frontal, superior temporal, pre-central, inferior parietal, hippocampus (CA1), subiculum, entorhinal cortex, transentorhinal cortex, inferior temporal, amygdala and basal forebrain. For each cortical area, a neuropathologist scanned the cortex over the entire slide, picked the most involved area, and then counted neuritic plaques stained with a Bielschowsky stain using the 10x ocular and 10x objective lenses. Each cortical region received a severity rating based on the following: 1 , if there were less than 5 neuritic plaques, 2 , if the number of neuritic plaques was between 5 and 15 and 3, if there were more than 15 neuritic plaques. We derived the total cortical neuritic plaque severity rating from the individual rating of each cortical region as follows: 1 , if the total neuritic plaque rating was mild (i.e. the majority of cortical areas contained fewer than $5 \mathrm{~A} \beta$ plaques), 2 , if the total neuritic plaque rating was moderate (i.e. the majority of cortical areas contained between 5 and $15 \mathrm{~A} \beta$ plaques) and 3 , if the total neuritic plaque rating was severe (i.e. the majority of cortical areas contained more than $15 \mathrm{~A} \beta$ plaques). White matter tissue immunostained with $A \beta$ antibodies from each case included in the study was also examined for the presence of white matter neuritic plaques, but none were found in any section.

\section{Data analysis}

Data were first analyzed with a repeated measures analysis of variance (ANOVA), with Region (2 levels: Anterior, posterior) as a within-subjects variable and Group (2 levels: $\mathrm{AD}$, control) as a between-subjects variable. Two separate ANOVAs were conducted for $A \beta-40$ levels and A $\beta-42$ levels. Age at death was included as a covariate. In order to investigate further the effect of region, the nonparametric Wilcoxon signed rank sum test was used. To study the relationship between white matter $A \beta$ levels and cortical plaque burden, Pearson correlations were calculated between white matter $A \beta$ levels and neuritic plaque severity rating in several cortical areas. To investigate whether white matter levels of soluble $A \beta$ were different between $\mathrm{AD}$ cases and non-AD controls, independent of cortical plaque pathology, a measure of total cortical neuritic plaque severity was included as a covariate and each 
ANOVA was re-run to test if the effect of either Group (AD vs. control) or Region (anterior vs. posterior) was still statistically significant.

\section{Results}

\section{A $\beta-40$ levels}

$\mathrm{AD}$ patients had higher average white matter $A \beta-40$ levels than non-AD controls (main effect of Group: $\mathrm{F}(1,15)=6.338, p=0.024$; Figure $1 \mathrm{~A}) . \mathrm{A} \beta-40$ levels did not differ between anterior and posterior white matter regions in either the overall ANOVA (main effect of Region: $\mathrm{F}(1,15)=0.718, p=0.410$; Figure $2 \mathrm{~A}$ ) or when the regional effect was further probed using a Wilcoxon signed-ranks test $(\mathrm{Z}=-0.675, p=0.500)$. There was not an interaction between group and region (Group $\mathrm{x}$ Region interaction: $\mathrm{F}(1,15)=0.003, p=0.957)$. No significant correlations were found between either anterior or posterior white matter levels of $A \beta-40$ and neuritic plaque severity rating in any cortical region (Table 2). After statistically controlling for total cortical neuritic plaque severity, Alzheimer's patients still had higher average white matter $A \beta-40$ levels than non-Alzheimer's controls (main effect of Group: $\mathrm{F}(1,14)=6.312, p=0.025$ ). After statistically controlling for total cortical neuritic plaque severity, there was still neither a main effect of region $(\mathrm{F}(1,14)=0.940, p=0.349)$ nor an interaction
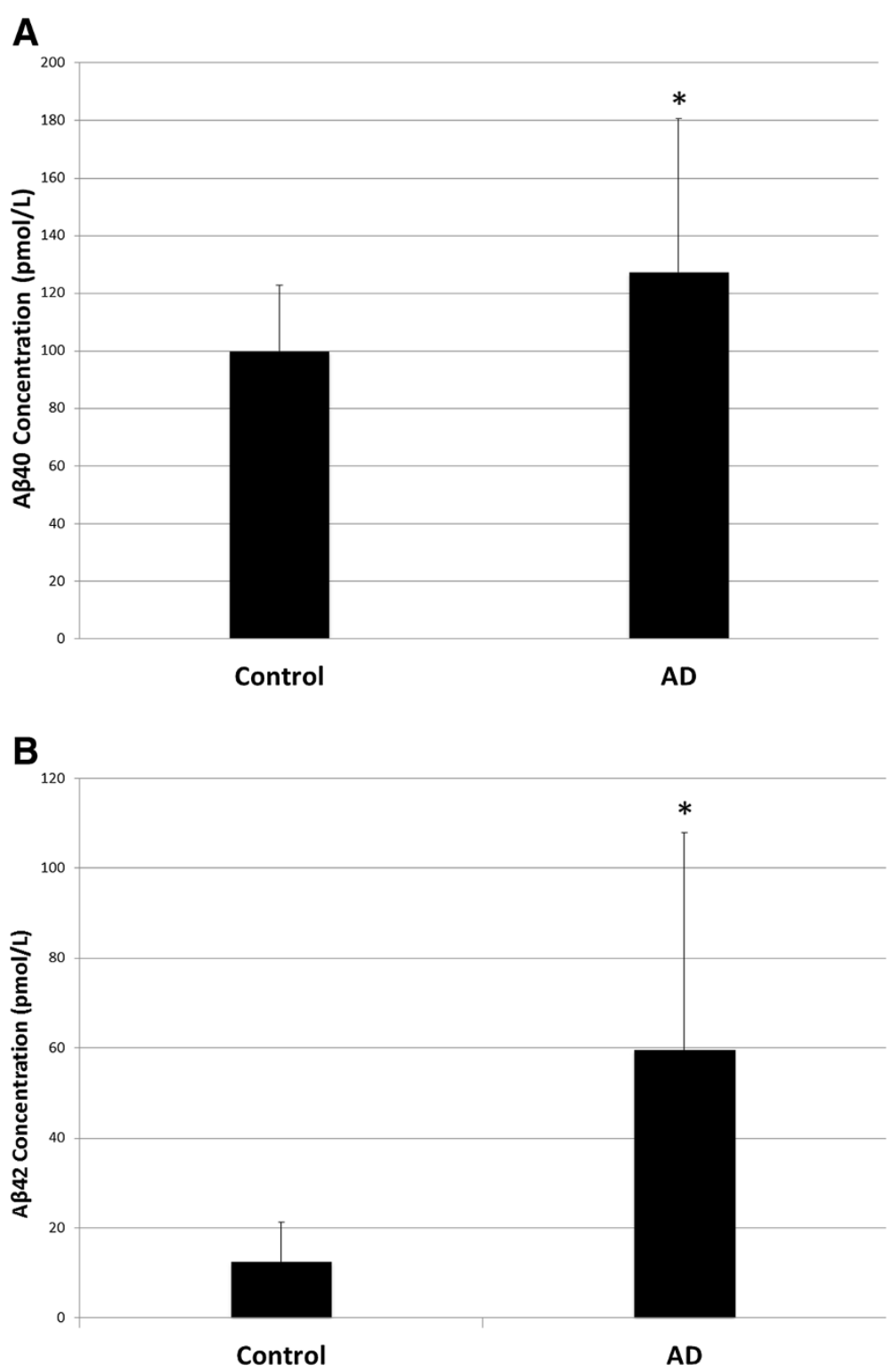

Figure 1 Main effect of group. (A) Average $A \beta-40$ levels were higher in the white matter of AD patients compared with non-AD controls. (B) $A \beta-42$ levels were significantly higher in the white matter of AD patients compared with non-AD controls. 

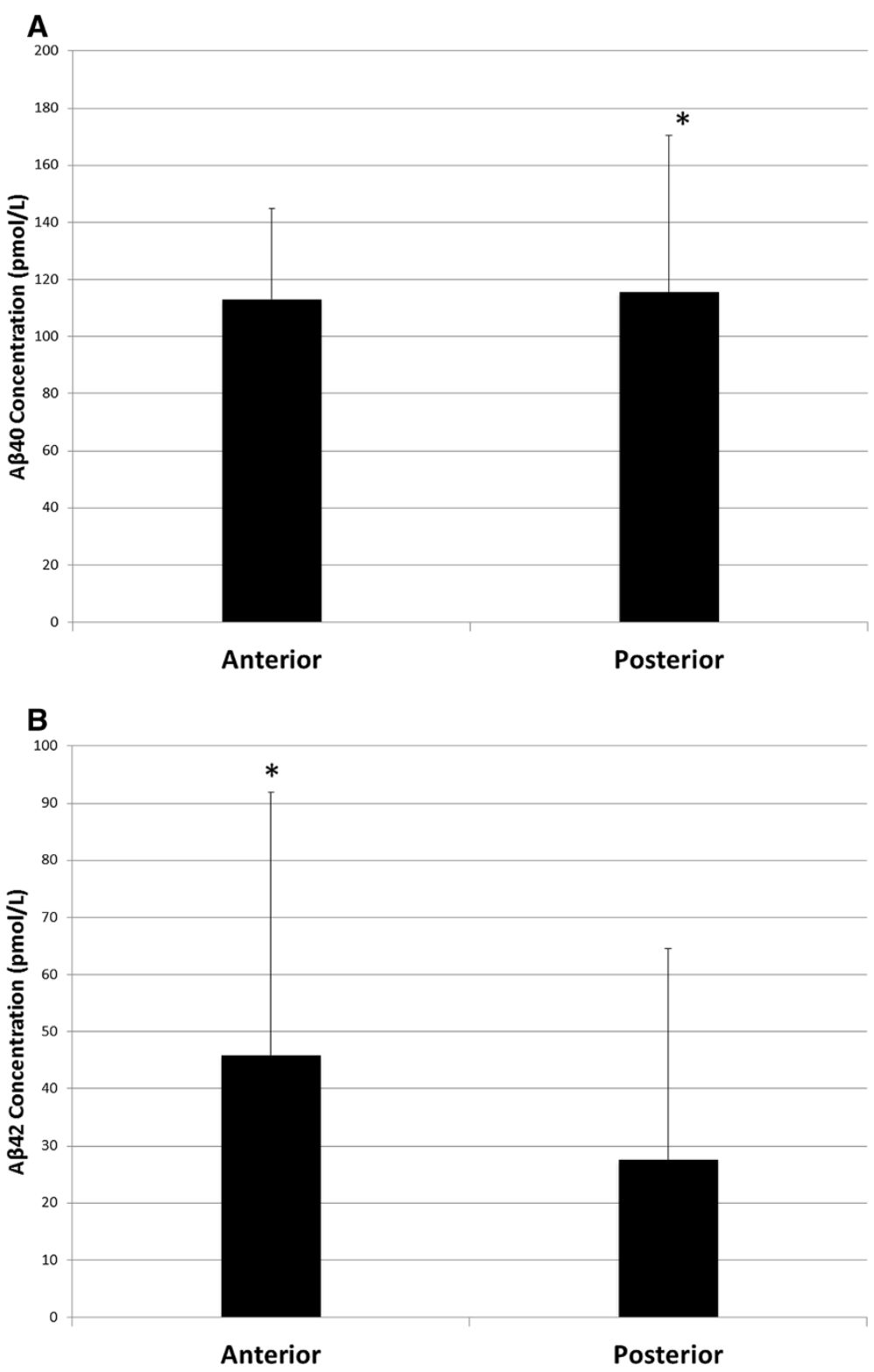

Figure 2 Main effect of region. (A) A $\beta$-40 levels were not significantly different in anterior or posterior regions of white matter. (B) There was a trend for $A \beta-42$ levels to be increased in anterior regions of white matter compared to posterior regions.

between group and region (Group $\mathrm{x}$ Region interaction: $\mathrm{F}(1,14)=0.141, p=0.713)$.

\section{A $3-42$ levels}

Compared with non-AD controls, $\mathrm{AD}$ patients had higher average levels of $A \beta-42$ (main effect of Group: $\mathrm{F}(1,15)=8.024, p=0.013$; Figure 1B). While $\mathrm{A} \beta-42$ levels were not different in anterior and posterior white matter regions (main effect of Region: $\mathrm{F}(1,15)=1.001, p=0.333$; Figure $2 \mathrm{~B}$ ), there was a trend for them to be higher in anterior than in posterior regions (anterior: $\mathrm{M}=45.84 \mathrm{pmol} / \mathrm{L}$, $\mathrm{SD}=46.06 \mathrm{pmol} / \mathrm{L}$; posterior: $\mathrm{M}=27.56 \mathrm{pmol} / \mathrm{L}$, $\mathrm{SD}=37.03 \mathrm{pmol} / \mathrm{L})$. This effect was further examined using a Wilcoxon signed-ranks test, which demonstrated that $A \beta-42$ levels were significantly higher in anterior regions compared with posterior regions $(\mathrm{Z}=-2.243$, $p=0.025)$. There was not a significant interaction between group and region (Group $\mathrm{x}$ Region interaction: $\mathrm{F}(1,15)=2.246, p=0.155)$. Significant positive correlations were found between anterior white matter levels of $\mathrm{A} \beta-42$ and neuritic plaque severity rating in the midfrontal cortex, pre-central cortex, inferior parietal cortex, hippocampal CA1, subiculum, entorhinal cortex, transentorhinal cortex, inferior temporal cortex, the amygdala and the basal forebrain (Table 2). Posterior white matter levels of $A \beta-42$ were positively correlated with neuritic 
Table 2 Correlations between white matter $A \beta$ 40/42 levels (Anterior and posterior) and plaque severity rating, assayed by CERAD criteria, in several CNS regions

\begin{tabular}{|c|c|c|c|c|c|c|c|c|}
\hline & \multicolumn{2}{|c|}{ Ant. $A \beta-40$} & \multicolumn{2}{|c|}{ Post. $A \beta-40$} & \multicolumn{2}{|c|}{ Ant. $A \beta-42$} & \multicolumn{2}{|c|}{ Post. A $\beta-42$} \\
\hline & $r$ & $\mathbf{p}$ & $r$ & $p$ & $r$ & $p$ & $r$ & $\mathbf{p}$ \\
\hline Mid-frontal & 0.294 & 0.196 & 0.204 & 0.403 & 0.697 & $<0.001$ & 0.630 & 0.004 \\
\hline Superior temporal & -0.263 & 0.529 & 0.194 & 0.617 & 0.607 & 0.111 & 0.706 & 0.034 \\
\hline Pre-central & 0.042 & 0.862 & 0.244 & 0.329 & 0.497 & 0.026 & 0.413 & 0.087 \\
\hline Inferior Parietal & 0.351 & 0.118 & 0.228 & 0.347 & 0.744 & $<0.001$ & 0.633 & 0.004 \\
\hline Hipp-CA1 & 0.019 & 0.937 & 0.082 & 0.746 & 0.618 & 0.004 & 0.596 & 0.009 \\
\hline Subiculum & 0.282 & 0.228 & 0.347 & 0.159 & 0.457 & 0.043 & 0.448 & 0.062 \\
\hline Entorhinal & 0.227 & 0.336 & 0.348 & 0.158 & 0.478 & 0.033 & 0.498 & 0.035 \\
\hline Transentorhinal & 0.220 & 0.352 & 0.349 & 0.155 & 0.565 & 0.009 & 0.584 & 0.011 \\
\hline Inferior Temporal & 0.270 & 0.250 & 0.298 & 0.230 & 0.653 & 0.002 & 0.655 & 0.003 \\
\hline Amygdala & 0.365 & 0.103 & 0.132 & 0.591 & 0.618 & 0.003 & 0.482 & 0.037 \\
\hline Basal forebrain & 0.360 & 0.109 & -.024 & 0.922 & 0.442 & 0.045 & 0.169 & 0.488 \\
\hline
\end{tabular}

Note: Significant correlations are indicated by bolded text.

plaque severity rating in the mid-frontal cortex, superior temporal cortex, inferior parietal cortex, hippocampal CA1, entorhinal cortex, transentorhinal cortex, inferior temporal cortex and the amygdala (Table 2). After statistically controlling for total cortical neuritic plaque severity, average white matter $A \beta-42$ levels were still higher in $A D$ patients than in non-AD controls (main effect of Group: $\mathrm{F}$ $(1,14)=5.184, p=0.039)$. There was still neither a main effect of region $(\mathrm{F}(1,14)=1.513, p=0.239)$ nor an interaction between group and region (Group $\mathrm{x}$ Region interaction: $\mathrm{F}(1,14)=3.237, p=0.094$ ) after controlling for total cortical neuritic plaque severity.

\section{Discussion}

The current study investigated whether levels of soluble $A \beta$ peptide are increased in the white matter of $\mathrm{AD}$ patients compared with non-AD controls. Levels of both soluble $A \beta-40$ and $A \beta-42$ were higher in the white matter of $\mathrm{AD}$ patients, even after statistically controlling for cortical neuritic plaque severity. While no regional white matter differences were found in $A \beta-40, A \beta-42$ levels were higher in anterior regions than in posterior regions across both subject groups.

The finding that soluble $A \beta-40$ and $A \beta-42$ levels are increased in the white matter of $\mathrm{AD}$ patients is consistent with the hypothesis that the white matter degeneration seen in $A D$ could be due, in part, to the toxicity of $A \beta$ peptides [4]. A recent study by Horiuchi and colleagues found that soluble $A \beta$ at $10 \mu \mathrm{M}$ or higher reduced the survival of mature oligodendrocytes and affected myelin sheet formation in vitro [56]. Similarly, Roher and colleagues demonstrated that increased levels of $\mathrm{A} \beta$ peptides are associated with reductions in multiple myelin biochemical markers and axonal demyelination
[57]. In a triple transgenic mouse model, $A \beta-42$ led to loss of myelin integrity and increased apoptotic cell death of mouse oligodendrocyte precursor cells in vitro, an effect that was reversed through the use of a viral vector-conjugated $A \beta-42$ specific intracellular antibody [58]. Amyloid beta may have detrimental effects on white matter via oxidative stress and the activation of transcription factors, such as NF- $\mathrm{BB}$ and AP-1, which may cause tissue damage through a pro-inflammatory reaction [59]. Amyloid beta peptide may also activate neutral sphingomyelinase, leading to increases in the apoptogenic mediator ceramide [60].

The current study found significant correlations between $A \beta 42$ levels and neuritic plaque severity ratings in several cortical regions. Given the amyloid cascade hypothesis and the large increases in $\mathrm{A} \beta 42$ known to occur in $\mathrm{AD}[2,38]$, this relationship is not surprising. $A \beta 42$ is the predominant form of $A \beta$ in parenchymal plaques $[53,54]$ and $A \beta 42$ displays enhanced neurotoxicity compared to $A \beta 40$ [61-63]. Additionally, $A \beta 42$ is known to form fibrils faster than $A \beta 40$ [64]. While $A \beta 40$ exists as monomers, dimers, trimers and tetramers in rapid equilibrium, $A \beta 42$ preferentially forms pentamer and hexamer units, which assemble into higher-order oligomers and early protofibrils $[65,66]$. Hence, it was not unexpected that white matter $A \beta 42$ levels would be related to the severity of cortical plaque pathology. It is noteworthy, however, that levels of $A \beta-40$ and $A \beta-42$ were increased in $\mathrm{AD}$ patients compared with non-AD controls, even after statistically controlling for cortical neuritic plaque severity, indicating that white matter levels of $A \beta$ are higher in $A D$ patients than non- $A D$ controls, above and beyond cortical plaque pathology. These observations suggest that white matter $A \beta$ peptides contribute to disease pathophysiology, at least in 
part, independent of grey matter pathology. This observation is consistent with several recent studies that suggest that, rather than being secondary to grey matter degeneration (i.e. Wallerian-like degeneration), white matter structural changes in $\mathrm{AD}$ might precede the emergence of grey matter pathology [4]. Several recent neuroimaging studies showed the presence of widespread white matter deficits in patients with amnestic mild cognitive impairment (aMCI) [67], subjective cognitive impairment [68] and cognitively normal individuals who go on to develop aMCI [21], despite a lack of grey matter cortical atrophy. Neuropathological studies also indicated pathological alterations in white matter preceding grey matter atrophy $[23,33]$. In one neuropathological study, while widespread white matter degeneration was observed in the brains of preclinical $\mathrm{AD}$ patients, the grey matter structure was relatively unaltered; conversely, the brains of patients with endstage AD showed both grey and white matter changes [27]. Taken together, these findings would suggest that white matter disease might be an early event in the pathogenesis of $\mathrm{AD}$. In fact, Castano and colleagues recently hypothesized that $\mathrm{AD}$ pathogenesis may actually begin in the white matter with oligodendrocyte dysfunction and associated pathological changes precipitating $\mathrm{AD}$ dementia and its progression [26]. The investigation of the pathophysiological mechanisms of white matter structural impairments could thus be critical for the identification and treatment of individuals at a high risk for developing AD.

In addition to the current findings, several other studies highlighted the importance of frontal lobe $A \beta$ levels in disease pathology. In a postmortem study of patients with $\mathrm{AD}$, Chalmers and colleagues reported that parenchymal amyloid load was more predictive of white matter degeneration in the frontal lobe than degenerative vascular disease, cerebral amyloid angiopathy or APOE ع4 genotype [69]. Similarly, postmortem studies using antibodies to $A \beta$ identified the frontal cortex as a location for high amounts of amyloid deposition [70]. This observation is consistent with $\left[{ }^{11} \mathrm{C}\right]$-PIB PET scan studies, where the highest amount of uptake has been observed in the frontal cortex, indicating more severe amyloid deposition in the grey matter in this area [71]. It is important to note, however, that PIB scans can only reliably measure fibrillar forms of amyloid in grey matter regions. In the current study, soluble $A \beta$ levels were studied exclusively in white matter tissue. Neuroimaging studies from our group reported that it is WMH burden in posterior regions, not the frontal lobe, that is most predictive of incident clinical $\mathrm{AD}$ in the community and of the rate of cognitive decline in $\mathrm{AD}[9,10,35]$. Thus, it is possible that, while amyloid may have a propensity to deposit in frontal regions, it is macrostructural changes in posterior areas that may drive the clinical presentation of the disease.
One potential limitation of the current study is the relatively heterogeneous control group. In future studies, it would be interesting to include a larger number of neuropathologically normal controls, in order to investigate more thoroughly how white matter pathology differs between normal, healthy aging and AD. Another potential limitation of the study is that the concentration of soluble $A \beta$ in the cortex was not measured. While it is possible that cortical levels of soluble $A \beta$ may be more appropriate for direct comparison with white matter levels of soluble $A \beta$, previous studies have suggested that there is a reliable correlation between cortical levels of soluble $A \beta$ and both diffuse and neuritic plaques in the cortex in $\mathrm{AD}[72,73]$. Hence, in the current study, we chose to use a rating of neuritic plaque severity as our marker of cortical amyloid pathology. Given the growing body of evidence that it is the levels of soluble $A \beta$ oligomers, rather than insoluble $A \beta$ fibrils, that correlate with the extent of synaptic loss and the severity of cognitive impairment in $\mathrm{AD}[38,39,43]$, however, future studies should also investigate the correlation between cortical and white matter levels of soluble $A \beta$ oligomers.

\section{Conclusion}

The current study found that both $A \beta-42$ and $A \beta-40$ levels were higher in the white matter of $\mathrm{AD}$ brains compared with non-AD controls, even after statistically controlling for cortical neuritic plaque severity. These findings suggest that $A \beta$ peptides in white matter tissue accumulate independent of overall grey matter fibrillar amyloid pathology and are not simply a reflection of overall amyloid burden. Thus, white matter $A \beta$ peptides may contribute to disease pathophysiology, at least in part, independent of grey matter pathology. Additionally, while no regional white matter differences were found in $A \beta-40, A \beta-42$ levels were higher in anterior regions than in posterior regions across both subject groups. This observation may suggest that $A \beta-42$ has a propensity to deposit in frontal regions, although it is not yet clear if this is related to cognitive change, or if macrostructural changes in posterior areas, likely related to cerebrovascular or other factors, may be more important for the clinical presentation of the disease.

In conclusion, the results of the current study help to shed light on a potential pathological mechanism that may contribute to white matter abnormalities in $\mathrm{AD}$. Given that white matter change may be an early marker of disease, preceding grey matter atrophy, understanding the mechanisms and risk factors that may lead to white matter damage could provide a novel mechanism by which to identify those at high risk, allowing us to intervene earlier in the pathogenic process. 


\section{Abbreviations}

AD: Alzheimer's disease; Aß: Amyloid beta; NFT: Neurofibrillary tangle; MRI: Magnetic resonance imaging; WMH: White matter hyperintensity; DTI: Diffusion tensor imaging; ANOVA: Analysis of variance; aMCl: Amnestic mild cognitive impairment; NIA-RI: National Institute on Aging and Reagan Institute; NIA-AA: National Institute of Health-Alzheimer's Association.

\section{Competing interests}

The authors declare that there are no any sources of financial support or relationship(s) that may pose a competing interest for the current work.

\section{Authors' contributions}

All authors 1) have made substantial contributions to conception and design, or acquisition of data, or analysis and interpretation of data; 2) have been involved in drafting the manuscript or revising it critically for important intellectual content; 3 ) have given final approval of the version to be published; and 4) agree to be accountable for all aspects of the work in ensuring that questions related to the accuracy or integrity of any part of the work are appropriately investigated and resolved. Additional specific contributions are as follows: LEC-P conceptualized the study, carried out assays, conducted analyses, and drafted the manuscript. YF supervised and carried out assays. E.Y.G. coordinated the study, assisted with tissue preparation, and helped carry out assays. AW conducted tissue dissection and assisted with carrying out assays. AL coordinated the autopsy study for clinicopathological analysis. LSH oversaw clinical and autopsy studies. EC conducted pathological examination of tissue and gross dissection. JPV oversaw and conducted pathological examination, gross dissection, and diagnostics. PC supervised the study. JEG supervised the study. $\mathrm{AMB}$ conceptualized the study and drafted the manuscript.

\section{Acknowledgments}

This work was supported by grants from the Alzheimer's Association, the Taub Institute at Columbia University, the Mary E. Groff Surgical Medical Research and Education Charitable Trust Groff Foundation, and NIH (P50 AG008702, R01 AG034189). We are grateful to the New York Brain Bank for material support.

\section{Author details}

${ }^{1}$ Taub Institute for Research on Alzheimer's Disease and the Aging Brain, College of Physicians and Surgeons, Columbia University, 630 West 168th Street, New York, NY 10032, USA. '2Department of Anatomy and Pathology, University of Adelaide, Adelaide, South Australia, Australia. ${ }^{3}$ Department of Neurology, College of Physicians and Surgeons, Columbia University, New York, NY, USA. ${ }^{4}$ Department of Pathology and Cell Biology, College of Physicians and Surgeons, Columbia University, New York, NY, USA.

Received: 9 June 2014 Accepted: 4 July 2014 Published: 17 August 2014

\section{References}

1. Reitz C, Brayne C, Mayeux R (2011) Epidemiology of Alzheimer disease. Nat Rev Neurol 7(3):137-152. doi:10.1038/nrneurol.2011.2

2. Hardy J, Selkoe DJ (2002) The amyloid hypothesis of Alzheimer's disease: progress and problems on the road to therapeutics. Science 297(5580):353-356. doi:10.1126/science.1072994

3. Amlien IK, Fjell AM (2014) Diffusion tensor imaging of white matter degeneration in Alzheimer's disease and mild cognitive impairment Neuroscience. doi:10.1016/j.neuroscience.2014.02.017

4. Sachdev PS, Zhuang L, Braidy N, Wen W (2013) Is Alzheimer's a disease of the white matter? Curr Opin Psychiatry 26(3):244-251. doi:10.1097/ YCO.0b013e32835ed6e8

5. Balthazar ML, Yasuda CL, Pereira FR, Pedro T, Damasceno BP, Cendes F (2009) Differences in grey and white matter atrophy in amnestic mild cognitive impairment and mild Alzheimer's disease. Eur J Neurol 16(4):468-474. doi:10.1111/j.1468-1331.2008.02408.x

6. Guo X, Wang Z, Li K, Li Z, Qi Z, Jin Z, Yao L, Chen K (2010) Voxel-based assessment of gray and white matter volumes in Alzheimer's disease. Neurosci Lett 468(2):146-150. doi:10.1016/j.neulet.2009.10.086

7. Li S, Pu F, Shi F, Xie S, Wang Y, Jiang T (2008) Regional white matter decreases in Alzheimer's disease using optimized voxel-based morphometry. Acta Radiol 49(1):84-90. doi:10.1080/02841850701627181
8. Salat DH, Greve DN, Pacheco JL, Quinn BT, Helmer KG, Buckner RL, Fischl B (2009) Regional white matter volume differences in nondemented aging and Alzheimer's disease. Neuroimage 44(4):1247-1258. doi:10.1016/j. neuroimage.2008.10.030

9. Brickman AM, Honig LS, Scarmeas N, Tatarina O, Sanders L, Albert MS, Brandt J, Blacker D, Stern Y (2008) Measuring cerebral atrophy and white matter hyperintensity burden to predict the rate of cognitive decline in Alzheimer disease. Arch Neurol 65(9):1202-1208. doi:10.1001/archneur.65.9.1202

10. Brickman AM, Muraskin J, Zimmerman ME (2009) Structural neuroimaging in Altheimer's disease: do white matter hyperintensities matter? Dialogues Clin Neurosci 11(2):181-190

11. Chen YF, Wang H, Chu Y, Huang YC, Su MY (2006) Regional quantification of white matter hyperintensity in normal aging, mild cognitive impairment, and Alzheimer's disease. Dement Geriatr Cogn Disord 22(2):177-184. doi:10.1159/000094785

12. Scheltens P, Barkhof F, Valk J, Algra PR, van der Hoop RG, Nauta J, Wolters EC (1992) White matter lesions on magnetic resonance imaging in clinically diagnosed Alzheimer's disease. Evidence for heterogeneity. Brain 115(Pt 3):735-748

13. Yoshita M, Fletcher E, Harvey D, Ortega M, Martinez O, Mungas DM, Reed BR, DeCarli CS (2006) Extent and distribution of white matter hyperintensities in normal aging, MCl, and AD. Neurology 67(12):2192-2198. doi:10.1212/01.wnl.0000249119.95747.1f

14. Acosta-Cabronero J, Williams GB, Pengas G, Nestor PJ (2010) Absolute diffusivities define the landscape of white matter degeneration in Alzheimer's disease. Brain 133(Pt 2):529-539. doi:10.1093/brain/awp257

15. Bosch B, Arenaza-Urquijo EM, Rami L, Sala-Llonch R, Junque C, Sole-Padulles C, Pena-Gomez C, Bargallo N, Molinuevo JL, Bartres-Faz D (2012) Multiple DTI index analysis in normal aging, amnestic MCI and AD. Relationship with neuropsychological performance. Neurobiol Aging 33(1):61-74. doi:10.1016/j.neurobiolaging.2010.02.004

16. Damoiseaux JS, Smith SM, Witter MP, Sanz-Arigita EJ, Barkhof F, Scheltens $P$, Stam CJ, Zarei M, Rombouts SA (2009) White matter tract integrity in aging and Alzheimer's disease. Hum Brain Mapp 30(4):1051-1059. doi:10.1002/hbm.20563

17. Kiuchi K, Morikawa M, Taoka T, Nagashima T, Yamauchi T, Makinodan M, Norimoto K, Hashimoto K, Kosaka J, Inoue Y, Inoue M, Kichikawa K, Kishimoto T (2009) Abnormalities of the uncinate fasciculus and posterior cingulate fasciculus in mild cognitive impairment and early Alzheimer's disease: a diffusion tensor tractography study. Brain Res 1287:184-191. doi:10.1016/j.brainres.2009.06.052

18. Serra L, Cercignani M, Basile B, Spano B, Perri R, Fadda L, Marra C, Giubilei F, Caltagirone C, Bozzali M (2012) White matter damage along the uncinate fasciculus contributes to cognitive decline in AD and DLB. Curr Alzheimer Res 9(3):326-333

19. Sexton CE, Kalu UG, Filippini N, Mackay CE, Ebmeier KP (2011) A metaanalysis of diffusion tensor imaging in mild cognitive impairment and Alzheimer's disease. Neurobiol Aging 32(12):2322. e2325-2318. doi:10.1016/j.neurobiolaging.2010.05.019

20. Zhang Y, Schuff N, Du AT, Rosen HJ, Kramer JH, Gorno-Tempini ML, Miller BL, Weiner MW (2009) White matter damage in frontotemporal dementia and Alzheimer's disease measured by diffusion MRI. Brain 132(Pt 9):2579-2592. doi:10.1093/brain/awp071

21. Zhuang L, Sachdev PS, Trollor JN, Reppermund S, Kochan NA, Brodaty H, Wen W (2013) Microstructural white matter changes, not hippocampal atrophy, detect early amnestic mild cognitive impairment. PLoS One 8(3):e58887. doi:10.1371/journal.pone.0058887

22. Zhuang L, Wen W, Trollor JN, Kochan NA, Reppermund S, Brodaty H, Sachdev $P$ (2012) Abnormalities of the fornix in mild cognitive impairment are related to episodic memory loss. J Alzheimers Dis 29(3):629-639. doi:10.3233/JAD-2012-111766

23. Brun A, Englund E (1986) A white matter disorder in dementia of the Alzheimer type: a pathoanatomical study. Ann Neurol 19(3):253-262. doi:10.1002/ana.410190306

24. Beach TG, Walker R, McGeer EG (1989) Patterns of gliosis in Alzheimer's disease and aging cerebrum. Glia 2(6):420-436. doi:10.1002/glia.440020605

25. Bronge L, Bogdanovic N, Wahlund LO (2002) Postmortem MRI and histopathology of white matter changes in Alzheimer brains. A quantitative, comparative study. Dement Geriatr Cogn Disord 13(4):205-212. doi:57698

26. Castano EM, Maarouf CL, Wu T, Leal MC, Whiteside CM, Lue LF, Kokjohn TA, Sabbagh MN, Beach TG, Roher AE (2013) Alzheimer disease periventricular 
white matter lesions exhibit specific proteomic profile alterations. Neurochem Int 62(2):145-156. doi:10.1016/j.neuint.2012.12.001

27. de la Monte SM (1989) Quantitation of cerebral atrophy in preclinical and end-stage Alzheimer's disease. Ann Neurol 25(5):450-459. doi:10.1002/ ana.410250506

28. Englund E (1998) Neuropathology of white matter changes in Alzheimer's disease and vascular dementia. Dement Geriatr Cogn Disord 9(Suppl 1):6-12

29. Englund E, Brun A (1990) White matter changes in dementia of Alzheimer's type: the difference in vulnerability between cell compartments. Histopathology 16(5):433-439

30. Roher AE, Kuo YM, Esh C, Knebel C, Weiss N, Kalback W, Luehrs DC, Childress JL, Beach TG, Weller RO, Kokjohn TA (2003) Cortical and leptomeningeal cerebrovascular amyloid and white matter pathology in Alzheimer's disease. Mol Med 9(3-4):112-122

31. Scheltens P, Barkhof F, Leys D, Wolters EC, Ravid R, Kamphorst W (1995) Histopathologic correlates of white matter changes on MRI in Alzheimer's disease and normal aging. Neurology 45(5):883-888

32. Sjobeck M, Haglund M, Englund E (2005) Decreasing myelin density reflected increasing white matter pathology in Alzheimer's disease-a neuropathological study. Int J Geriatr Psychiatry 20(10):919-926. doi:10.1002/gps.1384

33. Sjobeck M, Haglund $M$, Englund $E$ (2006) White matter mapping in Alzheimer's disease: A neuropathological study. Neurobiol Aging 27(5):673-680. doi:10.1016/.j.neurobiolaging.2005.03.007

34. Gunning-Dixon FM, Brickman AM, Cheng JC, Alexopoulos GS (2009) Aging of cerebral white matter: a review of MRI findings. Int J Geriatr Psychiatry 24(2):109-117. doi:10.1002/gps.2087

35. Brickman AM, Provenzano FA, Muraskin J, Manly JJ, Blum S, Apa Z, Stern Y, Brown TR, Luchsinger JA, Mayeux R (2012) Regional white matter hyperintensity volume, not hippocampal atrophy, predicts incident Alzheimer disease in the community. Arch Neurol 69(12):1621-1627. doi:10.1001/archneurol.2012.1527

36. Defrancesco M, Marksteiner J, Deisenhammer E, Kemmler G, Djurdjevic T, Schocke M (2013) Impact of white matter lesions and cognitive deficits on conversion from mild cognitive impairment to Alzheimer's disease. J Alzheimers Dis 34(3):665-672. doi:10.3233/JAD-122095

37. Solodkin A, Chen EE, Van Hoesen GW, Heimer L, Shereen A, Kruggel F, Mastrianni J (2013) In vivo parahippocampal white matter pathology as a biomarker of disease progression to Alzheimer's disease. J Comp Neurol 521(18):4300-4317. doi:10.1002/cne.23418

38. Cavallucci V, D'Amelio M, Cecconi F (2012) Abeta toxicity in Alzheimer's disease. Mol Neurobiol 45(2):366-378. doi:10.1007/s12035-012-8251-3

39. Haass C, Selkoe DJ (2007) Soluble protein oligomers in neurodegeneration: lessons from the Alzheimer's amyloid beta-peptide. Nat Rev Mol Cell Biol 8(2):101-112. doi:10.1038/nrm2101

40. Lue LF, Kuo YM, Roher AE, Brachova L, Shen Y, Sue L, Beach T, Kurth JH, Rydel RE, Rogers J (1999) Soluble amyloid beta peptide concentration as a predictor of synaptic change in Alzheimer's disease. Am J Pathol 155(3):853-862

41. McLean CA, Cherny RA, Fraser FW, Fuller SJ, Smith MJ, Beyreuther K, Bush Al, Masters CL (1999) Soluble pool of Abeta amyloid as a determinant of severity of neurodegeneration in Alzheimer's disease. Ann Neurol 46(6):860-866

42. Selkoe DJ (2002) Alzheimer's disease is a synaptic failure. Science 298(5594):789-791. doi:10.1126/science.1074069

43. Shankar GM, Walsh DM (2009) Alzheimer's disease: synaptic dysfunction and Abeta. Mol Neurodegener 4:48. doi:10.1186/1750-1326-4-48

44. Wang J, Dickson DW, Trojanowski JQ, Lee VM (1999) The levels of soluble versus insoluble brain Abeta distinguish Alzheimer's disease from normal and pathologic aging. Exp Neurol 158(2):328-337. doi:10.1006/exnr.1999.7085

45. Vonsattel JP, Del Amaya MP, Keller CE (2008) Twenty-first century brain banking. Processing brains for research: the Columbia University methods. Acta Neuropathol 115(5):509-532. doi:10.1007/s00401-007-0311-9

46. Mirra SS, Heyman A, McKeel D, Sumi SM, Crain BJ, Brownlee LM, Vogel FS, Hughes JP, van Belle G, Berg L (1991) The Consortium to Establish a Registry for Alzheimer's Disease (CERAD). Part II. Standardization of the neuropathologic assessment of Alzheimer's disease. Neurology 41(4):479-486

47. Braak H, Braak E (1991) Neuropathological stageing of Alzheimer-related changes. Acta Neuropathol 82(4):239-259
48. Consensus recommendations for the postmortem diagnosis of Alzheimer's disease (1997) The National Institute on Aging, and Reagan Institute Working Group on diagnostic criteria for the neuropathological assessment of Alzheimer's disease. Neurobiol Aging 18(4 Suppl):S1-S2

49. Hyman BT, Phelps CH, Beach TG, Bigio EH, Cairns NJ, Carrillo MC, Montine TJ National Institute on Aging-Alzheimer's Association guidelines for the neuropathologic assessment of Alzheimer's disease. Alzheimers Dement 8(1):1-13. doi:10.1016/j.jalz.2011.10.007

50. Kuo YM, Emmerling MR, Vigo-Pelfrey C, Kasunic TC, Kirkpatrick JB, Murdoch GH, Ball MJ, Roher AE (1996) Water-soluble Abeta (N-40, N-42) oligomers in normal and Alzheimer disease brains. J Biol Chem 271(8):4077-4081

51. Asami-Odaka A, Ishibashi Y, Kikuchi T, Kitada C, Suzuki N (1995) Long amyloid beta-protein secreted from wild-type human neuroblastoma IMR-32 cells. Biochemistry 34(32):10272-10278

52. Fukumoto $\mathrm{H}$, Tokuda $\mathrm{T}$, Kasai $\mathrm{T}$, Ishigami $\mathrm{N}$, Hidaka $\mathrm{H}$, Kondo $\mathrm{M}$, Allsop $\mathrm{D}$, Nakagawa M (2010) High-molecular-weight beta-amyloid oligomers are elevated in cerebrospinal fluid of Alzheimer patients. FASEB J 24(8):2716-2726. doi:10.1096/fj.09-150359

53. Iwatsubo T, Odaka A, Suzuki N, Mizusawa H, Nukina N, Ihara Y (1994) Visualization of $A$ beta $42(43)$ and $A$ beta 40 in senile plaques with end-specific A beta monoclonals: evidence that an initially deposited species is A beta 42(43). Neuron 13(1):45-53

54. Suzuki N, Cheung TT, Cai XD, Odaka A, Otvos L, Jr, Eckman C, Golde TE, Younkin SG (1994) An increased percentage of long amyloid beta protein secreted by familial amyloid beta protein precursor (beta APP717) mutants. Science 264(5163):1336-1340

55. Zhang C, Browne A, Divito JR, Stevenson JA, Romano D, Dong Y, Xie Z, Tanzi RE (2010) Amyloid-beta production via cleavage of amyloid-beta protein precursor is modulated by cell density. J Alzheimers Dis 22(2):683-984 doi:10.3233/JAD-2010-100816

56. Horiuchi M, Maezawa I, Itoh A, Wakayama K, Jin LW, Itoh T, Decarli C (2012) Amyloid beta1-42 oligomer inhibits myelin sheet formation in vitro. Neurobiol Aging 33(3):499-509. doi:10.1016/j.neurobiolaging.2010.05.007

57. Roher AE, Weiss N, Kokjohn TA, Kuo YM, Kalback W, Anthony J, Watson D, Luehrs DC, Sue L, Walker D, Emmerling M, Goux W, Beach T (2002) Increased $A$ beta peptides and reduced cholesterol and myelin proteins characterize white matter degeneration in Alzheimer's disease. Biochemistry 41(37):11080-11090

58. Desai MK, Mastrangelo MA, Ryan DA, Sudol KL, Narrow WC, Bowers WJ (2010) Early oligodendrocyte/myelin pathology in Alzheimer's disease mice constitutes a novel therapeutic target. Am J Pathol 177(3):1422-1435. doi:10.2353/ajpath.2010.100087

59. Xu J, Chen S, Ahmed SH, Chen H, Ku G, Goldberg MP, Hsu CY (2001) Amyloidbeta peptides are cytotoxic to oligodendrocytes. J Neurosci 21(1):RC118

60. Lee JT, Xu J, Lee JM, Ku G, Han X, Yang DI, Chen S, Hsu CY (2004) Amyloid-beta peptide induces oligodendrocyte death by activating the neutral sphingomyelinase-ceramide pathway. J Cell Biol 164(1):123-131. doi:10.1083/ jcb.200307017

61. Dahlgren KN, Manelli AM, Stine WB, Jr, Baker LK, Krafft GA, LaDu MJ (2002) Oligomeric and fibrillar species of amyloid-beta peptides differentially affect neuronal viability. J Biol Chem 277(35):32046-32053. doi:10.1074/jbc.M201750200

62. Selkoe DJ (1999) Translating cell biology into therapeutic advances in Alzheimer's disease. Nature 399(6738 Suppl):A23-A31

63. Younkin SG (1995) Evidence that A beta 42 is the real culprit in Alzheimer's disease. Ann Neurol 37(3):287-288. doi:10.1002/ana.410370303

64. Jarrett JT, Berger EP, Lansbury PT, Jr (1993) The carboxy terminus of the beta amyloid protein is critical for the seeding of amyloid formation: implications for the pathogenesis of Alzheimer's disease. Biochemistry 32(18):4693-4697

65. Bitan G, Kirkitadze MD, Lomakin A, Vollers SS, Benedek GB, Teplow DB (2003) Amyloid beta -protein (Abeta) assembly: Abeta 40 and Abeta 42 oligomerize through distinct pathways. Proc Natl Acad Sci U S A 100(1):330-335. doi:10.1073/pnas.222681699

66. Urbanc B, Betnel M, Cruz L, Bitan G, Teplow DB (2010) Elucidation of amyloid beta-protein oligomerization mechanisms: discrete molecular dynamics study. J Am Chem Soc 132(12):4266-4280. doi:10.1021/ja9096303

67. Agosta F, Pievani M, Sala S, Geroldi C, Galluzzi S, Frisoni GB, Filippi M (2011) White matter damage in Alzheimer disease and its relationship to gray matter atrophy. Radiology 258(3):853-863. doi:10.1148/radiol.10101284

68. Selnes P, Fjell AM, Gjerstad L, Bjornerud A, Wallin A, Due-Tonnessen P, Grambaite R, Stenset V, Fladby T (2012) White matter imaging changes 
in subjective and mild cognitive impairment. Alzheimers Dement 8(5 Suppl):S112-S121. doi:10.1016/j.jalz.2011.07.001

69. Chalmers K, Wilcock G, Love S (2005) Contributors to white matter damage in the frontal lobe in Alzheimer's disease. Neuropathol Appl Neurobio 31 (6):623-631. doi:10.1111/j.1365-2990.2005.00678.x

70. Thal DR, Rub U, Orantes M, Braak H (2002) Phases of A beta-deposition in the human brain and its relevance for the development of AD. Neurology 58(12):1791-1800

71. Klunk WE, Engler H, Nordberg A, Wang Y, Blomqvist G, Holt DP, Bergstrom M, Savitcheva I, Huang GF, Estrada S, Ausen B, Debnath ML, Barletta J, Price JC, Sandell J, Lopresti BJ, Wall A, Koivisto P, Antoni G, Mathis CA, Langstrom B (2004) Imaging brain amyloid in Alzheimer's disease with Pittsburgh Compound-B. Ann Neurol 55(3):306-319. doi:10.1002/ana.20009

72. van Helmond Z, Miners JS, Kehoe PG, Love S (2010) Oligomeric Abeta in Alzheimer's disease: relationship to plaque and tangle pathology, APOE genotype and cerebral amyloid angiopathy. Brain Pathol 20(2):468-480. doi:10.1111/j.1750-3639.2009.00321.x

73. Xia W, Yang T, Shankar G, Smith IM, Shen Y, Walsh DM, Selkoe DJ (2009) A specific enzyme-linked immunosorbent assay for measuring beta-amyloid protein oligomers in human plasma and brain tissue of patients with Alzheimer disease. Arch Neurol 66(2):190-199. doi:10.1001/archneurol.2008.565

\section{doi:10.1186/s40478-014-0083-0}

Cite this article as: Collins-Praino et al: Soluble amyloid beta levels are elevated in the white matter of Alzheimer's patients, independent of cortical plaque severity. Acta Neuropathologica Communications 2014 2:83.

\section{Submit your next manuscript to BioMed Central and take full advantage of:}

- Convenient online submission

- Thorough peer review

- No space constraints or color figure charges

- Immediate publication on acceptance

- Inclusion in PubMed, CAS, Scopus and Google Scholar

- Research which is freely available for redistribution 